\title{
Hotels' dependency on online intermediaries and their chosen distribution channel portfolios: three country insights
}

Article

Accepted Version

Creative Commons: Attribution-Noncommercial-No Derivative Works 4.0

Stangl, B., Inversini, A. and Schegg, R. (2016) Hotels' dependency on online intermediaries and their chosen distribution channel portfolios: three country insights. International Journal of Hospitality Management, 52. pp. 8796. ISSN 0278-4319 doi:

https://doi.org/10.1016/j.ijhm.2015.09.015 Available at https://centaur.reading.ac.uk/75361/

It is advisable to refer to the publisher's version if you intend to cite from the work. See Guidance on citing.

Published version at: https://doi.org/10.1016/j.jijhm.2015.09.015

To link to this article DOI: http://dx.doi.org/10.1016/j.ijhm.2015.09.015

Publisher: Elsevier

All outputs in CentAUR are protected by Intellectual Property Rights law, including copyright law. Copyright and IPR is retained by the creators or other copyright holders. Terms and conditions for use of this material are defined in the End User Agreement. 


\section{www.reading.ac.uk/centaur}

\section{CentAUR}

Central Archive at the University of Reading

Reading's research outputs online 


\section{Title Page}

Hotels' dependency on Online Intermediaries and their chosen Distribution

Channel Portfolios: Three country insights

Brigitte Stangl University of Surrey, School of Hospitality and Tourism Management

Stag Hill, Guildford, Surrey, GU2 7XH, United Kingdom

Email: b.stangl@surrey.ac.uk

(= Corresponding author)

Alessandro Inversini Bournemouth University, Faculty of Management

Fern Barrow, Bournemouth, BH12 5BB, United Kingdom

Email: ainversini@bournemouth.ac.uk

Roland Schegg Institute of Tourism, HES-SO Valais

TechnoPôle 3, 3960 Sierre, Switzerland

Email: roland.schegg@hevs.ch 


\section{Introduction}

In the competitive tourism environment (Michopoulou and Buhalis 2008) hospitality enterprises (e.g. Kang, Brewer, and Baloglu 2007) are exploiting various online distribution channels to increase their visibility (Buhalis 1999), to raise awareness and interest (Chan and Law 2006), and eventually to foster online purchasing (AbouShouk, Megicks, and Lim 2012). With the development of the Internet it was assumed that the importance of intermediaries would decrease (Bennett and Lai 2005; Tse 2003). It was predicted that a user-friendly and useful hotel website would boost the likelihood of selling products directly to the customers (Ip, Law, and Lee 2011). This prediction of dis-intermediation did not come true.

Many Online Travel Agencies (OTA) have been entering the market (Gazzoli, Kim, and Palakurthi 2008), increasing the complexity of the online distribution network (Kracht and Wang 2010). Consequently hospitality managers are faced with new challenges concerning marketing (Buhalis 2003) and selling (O'Connor and Frew 2004) services. This so called "re-intermediation" (Bennett and Lai 2005) results in a huge amount of online channels which are available in addition to traditional distribution channels, which in turn leads to an increasingly multifaceted distribution environment (Kracht and Wang 2010) challenging the hospitality industry. In order to stay competitive in this environment where customers can conveniently order the whole tourism experience in a "one-stop-shop" offered by OTAs (O'Connor 2008) and where the competitor is only one click away (Law 2009), hoteliers need to allocate scarce resources thoughtfully (Schegg et al. 2013) .

Some players in the distribution network have been gaining advantages due to their centrality (Zeng and Gerritsen 2014). They gained power in terms of controlling 
resources (Ford, Wang, and Vestal 2012; Pfeffer 1992). As a consequence less powerful players became dependent concerning their marketing decisions. This dependency, which is defined as the need to maintain relationships to achieve goals (e.g. Tourism Alliance 2014), implies an Information and Communication Technology (ICT) driven shift in the distribution power balance (Tourism Alliance 2014; Zeng and Gerritsen 2014). Some OTAs are taking control of hotels' allotments (Carroll and Siguaw 2003), marketing and pricing (Brewer et al. 2006), forcing hoteliers to constantly re-consider how they select OTAs (Kim, Bojanic, and Warnick 2009).

Depending on product and target market sophistication and resources-based issues (Coelho and Easingwood 2008) hotel managers need to allocate the right amount of products to the most relevant portfolio of offline (e.g., walk-ins) and online channels owned by the hoteliers (e.g., hotel website) as well as third party websites such as OTAs' platforms (Gazzoli, Kim, and Palakurthi 2008).

Up to now, there is a lack of research looking at the dependency of hotels on a specific Internet Distribution System (IDS) channel/category such as an OTA and the mix of offline and online distribution channels hoteliers choose. In order to better understand how hoteliers select an effective portfolio of channels, this research investigates OTA dependency and the distribution channel mix chosen in the hospitality sector. Due to differences between countries in terms of OTA popularity (Schegg 2014), pro-activeness and risk-taking attitudes (Brodbeck et al. 2000; Szabo et al. 2002), we look at three different countries namely Austria, Germany and Switzerland. In more detail the objective of this study is threefold: (i) to reveal predominant off- and online distribution channels adopted by hotel managers, (ii) to highlight the differences between Germany, Austria and Switzerland concerning the OTA penetration rate and hoteliers' dependency on OTAs (i.e. bookings generated), 
and (iii) to reveal the amount of channels used as well as differences in the three countries with regards to the portfolio of channels used.

In the following sections the literature review deals with setting the context of the study by discussing the development of online distribution, ICT driven distribution market developments, and power shifts in distribution networks. The results section presents descriptive findings concerning the role of various distribution channels; demonstrates the penetration rate and how many bookings are generated via different online channels; deals with how many channels are used and the distribution channel portfolio; and gives insights into differences between Germany, Austria and Switzerland. Finally, the theoretical discussion is followed by managerial implications.

\section{Literature Review}

Economics has dealt with distribution by looking at transaction costs (Nash 2001), management examined competitive strength, channel performance (Yan et al. 2011), bargaining power and profit sharing (Simchi-Levi, Wu, and Shen 2004), while marketing deals with market heterogeneity (Louvieris, Driver, and Powell-Perry 2003), positioning (Keller 2010), channel conflict (Pauwels and Neslin 2015) and global marketing strategies based on cross-cultural similarities (Kaynak and Herbig 2014; Martenson 1987).

In terms of cross-cultural similarities Brodbeck et al. (2000) found that leadership concepts are culturally endorsed. Austria, Germany and Switzerland share similar cultural values and thus have quite similar patterns concerning leadership (Thill, Venegas, and Groblschegg 2014). However, they differ concerning the importance of 'Humane Orientation' for outstanding leadership (Brodbeck et al. 2000). This is 
supported by Szabo et al. (2002) who revealed that in Switzerland the individual drives the society while in Germany and Austria the system promotes the individual.

The countries also differ in terms of entrepreneurial orientation and organizational performance: In Austria risk-taking and innovativeness are growth factors, whereas only innovativeness is influential on performance in Switzerland (Filser and Eggers 2014). Cultural differences exist between the three countries with regards to the social environment promoting innovativeness, pro-activeness and risk-taking attitudes. Thus, considering country differences in the context of online distribution is important (Law et al. 2015).

\subsection{The development of online distribution}

Since the 1990s, the Internet has been changing the way in which business is conducted in the hospitality industry (Buhalis and Law 2008; O'Connor and Frew 2004). The development of Computer Reservation Systems (CRS - 1970s), Global Distribution Systems (GDS - 1980s), and the advent of the Internet (1990s) generated a paradigm shift and a change of the distribution management in the industry (Buhalis and Law 2008; Ip, Law, and Lee 2011, 2011).

Brewer, Feinstein, and Bai (2006) emphasize that Small and Medium sized Hospitality Enterprises (SMHEs) are of particularly interest when discussing the role of distribution management. Looking at the small and medium sized structured hospitality sector several authors provide evidence that the fragmentation caused a reluctance in terms of embracing the Internet (e.g. Law and Jogaratnam 2005; Morosan and Jeong 2008; Toh, Raven, and DeKay 2011). Nowadays hotel managers recognize not only pre-WWW area distribution channels (Scaglione and Schegg 2015) but also the advantages of the Internet in terms of fostering 
customized marketing activities (Lau et al. 2001) and engaging in sales by using cheaper and frequently accessed online channels (O'Connor and Frew 2004; Brown and Kaewkitipong 2009). In 2009 Law, reported that the Internet has revolutionized the way business was conducted.

A growing body of literature has been focusing on online distribution (e.g. Werthner and Ricci 2004) as alternative to increase bookings and revenue (Ball and Queyranne 2009). Research also looked at the importance of accommodation websites (Law and Hsu 2006) and the significance of a coherent web presence (Chung and Law 2003), which is perceived as a crucial factor for success. Brewer, Feinstein, and Bai (2006) confirmed the significance of websites and identified rate control, staff education, customer loyalty, and the control of the hotel image as further challenges hoteliers face.

More recently, part of the academic discussion about online distribution shifted towards the use of social media for engaging with prospective (Filieri and McLeay 2013; Inversini and Masiero 2014) and loyal consumers (Vermeulen and Seegers 2009), the effective use of OTAs and the selection of IDSs in general (Lee, Guillet, and Law 2013; Schegg et al. 2013).

\subsection{ICT driven distribution market developments}

In 2002 online distribution was seen as a promising shift away from traditional sales channels such as walk-ins and telephone (Kasavana and Singh 2001; O'Connor and Frew 2002). In 2004 Werthner and Ricci reported that tourism had become the top industry in terms of online transactions volume. In 2007 Starkov and Price, recorded 
that two out of three reservations were made online (i.e. actual transactions) or were influenced by the Internet (i.e. people search online but make reservations over the phone, doing what is called "cross-channel free-riding", - Chiu et al. 2011; Starkov and Price 2007). In 2009 TraveICLICK analysed thirty international brands/chains and revealed that the majority of hotel reservations (48\%) was done online. While traditional storefront travel agents and traditional channels contribute $27 \%$ and $25 \%$ respectively.

In the last years the online travel market experienced a faster growth than the entire travel market (PhoCusWright 2011). This is driven by tourists who nowadays are aware of the variety of choices they have; they are more demanding, more knowledgeable about traveling (Buhalis and Law 2008) and about information search (Xiang, Wöber, and Fesenmaier 2008). Due to the change of tourist behaviour the importance of online distribution has been growing exponentially (Marcussen 2008).

Toh, Raven, and DeKay (2011) summarized the main reasons pertaining to the growth of the Internet as a booking channel: (i) it is a valuable channel for intangible goods, (ii) customers expect goods sold online to be cheaper, (iii) it allows for quick price comparisons and decreased search costs, and (iv) customers can bypass travel agencies and connect directly with the seller.

\section{$\underline{2.3 \text { Power shifts in distribution networks }}$}

The market consists of a network of distribution channel members, which are related to each other (Coughlan et al. 2001). Some channel members have the power to make decisions without considering the interests of other members (Brown, Lusch, and Muehling 1983). The power of a specific organization depends on how much control it has over critical resources, its allies and supporters, its reputation, and on 
how centrally it is positioned in a certain distribution network (Ford, Wang, and Vestal 2012; Pfeffer 1992).

The raise of ICT, related changes of consumer behaviour (Mills and Law 2013) and the market, affects hotels as well as other stakeholders in the distribution network unequally - leading to shifts in power (Werthner and Ricci 2004). Some players in the distribution network gain power at the expense of others, which may lead to dependencies (Pearce 2008). Dependency is defined as the need to maintain relationships to achieve goals (Tourism Alliance 2014). This means pricing, product policies and other marketing activities of the dependent organization can be influenced by the more powerful players (Toh, Raven, and DeKay 2011). Distributors who use ICT to tailor their products according to customers' needs will be able to increase their power (Berne, Garcia-Gonzalez, and Mugica 2012). They will gain a more central position, allowing them to take power from other network members (e.g. Lowe et al. 2012). Berne et al. (2012) show that ICT induced changes of the power balance between channels depend on the market structure (i.e., number, size, concentration, and integration of distributors and final buyers) but not on the channel structure (i.e., issues of relationships between channel participants). In other words, only market structures changes affect the power of network members. Unfortunately, the survey by Berne et al. (2012) does not include the growing group of intermediaries of "only-OTAs" (e.g., Priceline); a group which recently gets a lot of attention and power and who has been contributing to structural changes.

"Only-OTAs" (e.g., Expedia, Travelocity) emerged in the 1990s. They are third-party companies that have become increasingly powerful in terms of Internet readiness (Morosan and Jeong 2008) and economic force. They put hotels in a disadvantaged position by 'forcing' them to sell a large portion of their inventory through 
intermediaries, often at discounted rates (Carroll and Siguaw 2003). OTAs sell products from several suppliers, offering consumers a 'one-stop-shop' where they can purchase the whole travel experience (O'Connor and Frew 2002). OTAs have also built their past success on the possibility of building economies of scope, aggregating products and reducing costs to provide the final consumers with cheaper solutions (Kim, Bojanic, and Warnick 2009). Different business models, such as merchant- and opaque models (Enz 2003; Kang, Brewer, and Baloglu 2007) and smart business practices (related for instance to pricing - Tso and Law 2005;

Enz 2003) enable OTAs to provide better deals than hotels on their websites (Gazzoli, Kim, and Palakurthi 2008). Further, OTAs take advantage of knowledge they gain through data mining allowing them to tailor direct mail campaigns and loyalty programs accordingly (Toh, Raven, and DeKay 2011).

OTAs ability to create customer value and to deliver convenience in terms of information search and booking (Palmer and McCole 1999) led to a range of challenges for hoteliers. Buhalis (2000) revealed one-sided legal coverage, payment delays and techniques how tour operators' impact on pricing as the main challenges. With increasing dependency on OTAs these aspects are becoming more severe and consequently hoteliers lose control over their own products and brands. Hoteliers need to review their relationships in distribution networks regularly, to make sure that they not only benefit in terms of exposure to the market but also to maximize the share of the total value gained from being part of a network (Ford, Wang, and Vestal 2012). In order to manage inter-organizational power, it is important to have an understanding of the channel mix chosen and the dependency on certain channels (Kang, Brewer, and Baloglu 2007). It is essential to strategically choose a manageable amount of channels rather than adding them ad infinitum (O'Connor 
and Frew 2004) and randomly on an ad hoc basis (Cespedes and Corey 1990). In order to derive a balanced distribution channel strategy, Coelho and Easingwood (2003) suggest to have an understanding of the number of channels used, the mix of self-owned (e.g., hotel website) and third party websites (e.g. OTAs) as well as the contact with customers (see Figure 1).

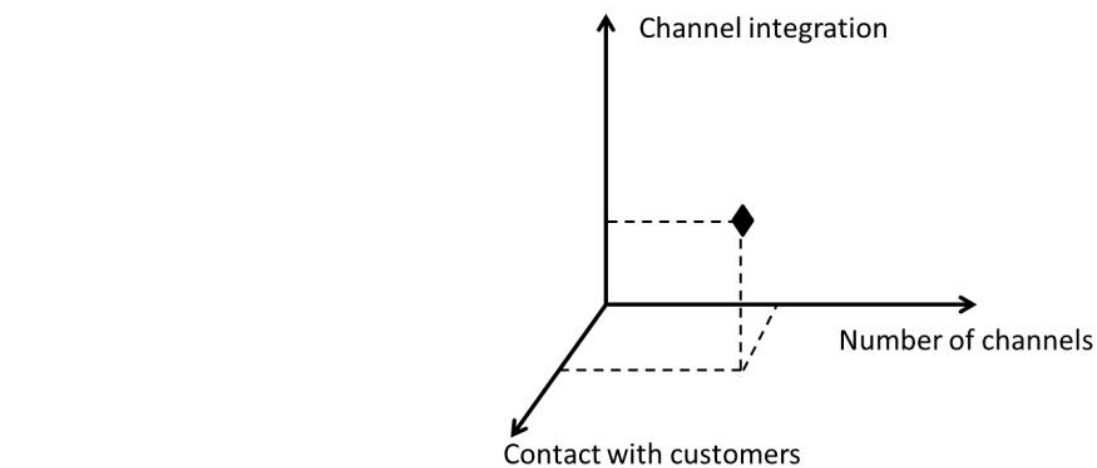

Figure 1: Key properties of a multichannel structure (Coelho and Easingwood 2003)

A closer look at the actual status quo of the OTA market reveals a market situation where a handful of big players present themselves on the market with different brands to target different segments. As presented in Table 1, this means that in many cases different websites are owned/operated by a few "travel-booking giants".

Table 1. OTA parent brands and their sub-brands

\begin{tabular}{|l|l|l|}
\hline Parent brand & Sub-brands & Source \\
\hline HRS Group & HRS, hotel.de, SURPRICE Hotels, and Tiscover & (HRS Group, 2014) \\
\hline $\begin{array}{l}\text { Expedia } \\
\text { Incorporation }\end{array}$ & $\begin{array}{l}\text { Expedia, Hotels.com, Expedia Affiliate Network } \\
\text { (EAN), Egencia Hotwire, eLong, Trivago, Venere, } \\
\text { CarRentals.com, Classic Vacations, Expedia } \\
\text { CruiseShip Centers, Expedia Local Expert }\end{array}$ & (EXPEDIA INC, 2014) \\
\hline $\begin{array}{l}\text { Priceline } \\
\text { Group }\end{array}$ & $\begin{array}{l}\text { Booking.com, priceline.com, agoda.com, KAYAK, } \\
\text { rentalcars.com, and OpenTable }\end{array}$ & (Priceline Group, 2014) \\
\hline $\begin{array}{l}\text { Sabre } \\
\text { Holdings } \\
\text { Corporation }\end{array}$ & $\begin{array}{l}\text { Sabre, Sabre Holdings, Sabre Travel Network, } \\
\text { Sabre Airline Solutions, Sabre Hospitality Solutions, } \\
\text { GetThere, Travelocity, Travelocity Business, } \\
\text { lastminute.com, holidayautos.com, IgoUgo, Zuji, } \\
\text { cubeless and WorldChoiceTravel }\end{array}$ & (Sabre Holdings Corp., \\
\hline Orbitz & Orbitz, CheapTickets, ebookers, HotelClub, & (Orbiz Worldwide, 2014) \\
\hline
\end{tabular}




\begin{tabular}{|l|l|l|}
\hline Worldwide & $\begin{array}{l}\text { RatesToGo, the Away Network, MrJet, Asia Hotels } \\
\text { and Orbitz for Business }\end{array}$ & \\
\hline $\begin{array}{l}\text { Hotelplan } \\
\text { Holding }\end{array}$ & $\begin{array}{l}\text { Hotelplan Suisse (MTCH AG), Hotelplan Italia } \\
\text { S.p.A., Hotelplan UK Group Ltd., Interhome AG, } \\
\text { Inter Chalet Ferienhaus-Gesellschaft GmbH, bta } \\
\text { first travel ag and Travelwindow AG }\end{array}$ & (Hotelplan Holding, 2014) \\
\hline
\end{tabular}

Looking at various OTAs hoteliers use in different countries, shows that the dependency rate differs. The most important player for Germany is HRS followed by Hotel.de, Booking.com and Expedia (Top Hotel, 2008). In Austria and Switzerland not even 10\% use HRS; Booking.com is the strongest channel. A platform popular in Austria only is Tiscover, while Venere is more common in Switzerland. Generally, the market share of OTAs is higher in Germany and Switzerland than in Austria, which means Austrian hoteliers are more independent (Schegg 2014; Top Hotel 2008). This shows that one needs to look at OTA peculiarities of different countries.

\section{Research Questions}

Following Coelho and Easingwood's (2003) framework, the aim of this research is to investigate the number of channels used and the mix and integration of various offline and online channels. In doing so we also reveal the penetration rate of OTAs (i.e., percentage of hotels using a certain OTA; Forlani and Parthasarathy 2003) and hotelier's dependency on OTAs in terms of bookings generated (Ford, Wang, and Vestal 2012; Pfeffer 1992). Due to differences concerning the importance of channels (Schegg 2014; Top Hotel 2008), innovativeness, pro-activeness and risktaking attitudes (Brodbeck et al. 2000; Filser and Eggers 2014) between Germany, Austria and Switzerland we will focus on the following three research questions: 
RQ1: How many channels do hoteliers select and what role do various distribution channels play on the Austrian, German and Swiss hospitality market?

RQ2: Are there differences between hoteliers concerning the OTA penetration rate and hoteliers' dependency on OTAs in Austria, Germany and Switzerland?

$$
\text { RQ3: Are there differences between hoteliers with regards to the portfolio of }
$$
distribution channels chosen in Austria, Germany and Switzerland?

Literature demonstrated that the power balance between various channels depend on the market structure (Berne, Garcia-Gonzalez, and Mugica 2012). Thus, for RQ3 distribution channel portfolio clusters will be detected and profiles based on star rating, amount of rooms offered, target group (i.e., leisure vs. business travellers), ownership (i.e., independent vs. chains/corporations) and the amount of channels used will be revealed.

\section{Methodology}

The questionnaire developed comprises a question concerning how bookings are distributed among available direct (telephone, fax, walk-in, etc.) and indirect (tour operator, tourism office, GDS, OTA etc.) channels. Hoteliers specified how much each channel accounts for in percentages. Another question, asks hoteliers to specify the market shares of OTAs such as Booking.com, Expedia, and HRS (the most important channels in the three countries (Top Hotel, 2008)). There was also an option "other", supposing hotelier's use other OTAs than the most important OTAs listed. The final part covers questions about star rating, the size of the hotel in 
273 terms of rooms offered, amount of overnight stays, location, main target group (i.e.,

274 leisure or business travellers), and number of opening days in the year 2011.

275 After a pre-test the online questionnaire was distributed. Data collection was done in collaboration with the hoteliers' associations DEHOGA (Germany, DE), ÖHV

277 (Austria, AT), and hotelleriesuisse (Switzerland, $\mathrm{CH}$ ). In total, the survey was sent twice to 11'751 hotels. The first invitation email was sent in December 2011 followed by a reminder in January 2012.

\subsection{Data Analysis}

282 The data is analysed in a descriptive way and different segments are revealed with the Typology Representing Network TRN-32 toolkit (Mazanec 2008).

This research will be one of the few studies applying data driven segmentation in a supply side context. It is also a rare example of cluster analyses providing external validation of the results based on various data sets from different countries (e.g., Tkaczynski and Prebensen 2012). We further follow Dolnicar's (2002) suggestion to test cluster reliability and stability.

The segmentation basis related to RQ3 is the usage of various distribution channels, i.e., traditional distribution (telephone, fax, letters, walk-ins), electronic requests (email, web booking form), online booking (GDS, IDS/OTA, direct booking on hotel website, hotel chains with CRS, social media), and tourism partners (tour operators, DMO national-local, event \& conference organizers). The Euclidean distance is used. In order to profile the clusters ANOVAs and cross-tabs applying Monte Carlo 
simulation, to account for cells with low counts, are applied (95\% confidence interval; number of samples: 10'000).

\section{Results}

\section{$\underline{5.1 \text { Sample description }}$}

Overall 1'014 questionnaires were usable for the purpose of this analysis (response rate $\mathrm{AT}=9.7 \%, \mathrm{DE}=12.8 \%$, and $\mathrm{CH}=10.1 \%)$. The sample sizes for the three countries are $n_{A T}=117, n_{D E}=701$, and $n_{C H}=196$. The sample covers all different star rating categories. The average number of rooms is 45.2 . The majority of $74.4 \%$ are independent hotels. Looking at room numbers and the hotel's ownership, a $\chi^{2}$ goodness-of-fit test proves that the sample is representative $\left(\chi^{2}=2.9243, p=0.087\right.$ and $\left.\chi^{2}=0.121, p=0.7275\right)$. In terms of opening days per year, the mean is 336.8. Of all hotels, $44.3 \%$ said to be city hotels; some did not specify. Regarding the target groups, $43.1 \%$ specified leisure travellers as their main target group; a small share focuses on "other target groups". Details about country differences are summarized

310 in Table 2.

Table 2. Sample description for Germany, Austria and Switzerland

\begin{tabular}{lcccc} 
& $\begin{array}{c}\text { Overall } \\
\left(\mathrm{n}=1^{\prime} 014\right)\end{array}$ & $\begin{array}{c}\text { Germany } \\
(\mathrm{n}=701)\end{array}$ & $\begin{array}{c}\text { Austria } \\
(\mathrm{n}=117)\end{array}$ & $\begin{array}{c}\text { Switzerland } \\
(\mathrm{n}=196)\end{array}$ \\
\hline Not rated or no stars & $22.9 \%$ & $28.8 \%$ & $4.3 \%$ & $11.2 \%$ \\
$1^{*} 2^{*}$ hotels & $5.8 \%$ & $5.4 \%$ & $1.7 \%$ & $9.7 \%$ \\
$3^{*}$ hotels & $43.2 \%$ & $44.2 \%$ & $25.6 \%$ & $50.0 \%$ \\
$4^{*}$ hotels & $24.5 \%$ & $19.5 \%$ & $66.7 \%$ & $16.8 \%$ \\
$5^{*}$ hotels & $1.7 \%$ & $1.1 \%$ & $0.9 \%$ & $4.1 \%$ \\
\hline$\varnothing$ number of rooms & 45.2 & 41.5 & 58.7 & 60.0 \\
Min/ max number of rooms & $3 / 600$ & $3 / 485$ & $7 / 252$ & $6 / 600$ \\
\hline Independent hotel & $74.4 \%$ & $78.2 \%$ & $70.9 \%$ & $62.8 \%$ \\
Hotel cooperation & $17.0 \%$ & $15.4 \%$ & $17.9 \%$ & $21.9 \%$ \\
Hotel chain & $6.5 \%$ & $4.7 \%$ & $9.4 \%$ & $11.2 \%$ \\
\hline$\varnothing$ number of opening days & 336.8 & 346.5 & 309.0 & 320.3 \\
\hline
\end{tabular}




\begin{tabular}{lllll}
\hline Share of leisure & $43.1 \%$ & $32.7 \%$ & $74.4 \%$ & $61.7 \%$ \\
Share of business guests & $46.9 \%$ & $55.5 \%$ & $19.7 \%$ & $32.7 \%$ \\
\hline Share of city hotels & $44.3 \%$ & $49.5 \%$ & $29.1 \%$ & $34.7 \%$ \\
Share of resort hotels & $33.6 \%$ & $24.8 \%$ & $59.0 \%$ & $50.0 \%$
\end{tabular}

\section{$\underline{5.2 \text { The role of various distribution channels (RQ1) }}$}

Overall, direct bookings, which are made through telephone, fax, walk-ins, e-mail, a form or a booking engine on hotel websites, are the dominant sales channels accounting for $66.34 \%$. The highest share of direct bookings are generated in Austria (68.89\%) followed by Switzerland (66.44\%) and Germany (65.89\%). Figure 2 shows that telephone, fax, letters, and walk-ins (i.e., traditional channels) are the most important distribution channels in Germany (36.45\%) and Switzerland (29.40\%). In Austria, $27.24 \%$ of times, distribution is done via email followed by traditional channels (21.92\%). On average, about one fifth (21.89\%) of all bookings are generated electronically in real-time through IDS; Swiss guests (19.93\%) use this channel more often than guests in Germany (21.89\%) and Austria (13.68\%). Nearly $5 \%$ of Swiss bookings are done through DMOs; less often in the other two countries. Austria leads the ranking in terms of bookings via Tour Operators/Travel Agents and website based (i.e., form and real-time) bookings. Social media does generate only a marginal amount of bookings in all three countries. On average a mix of 8.06 channel categories is used to distribute hotels with a maximum of 15 and a minimum of one (STD=2.25). 


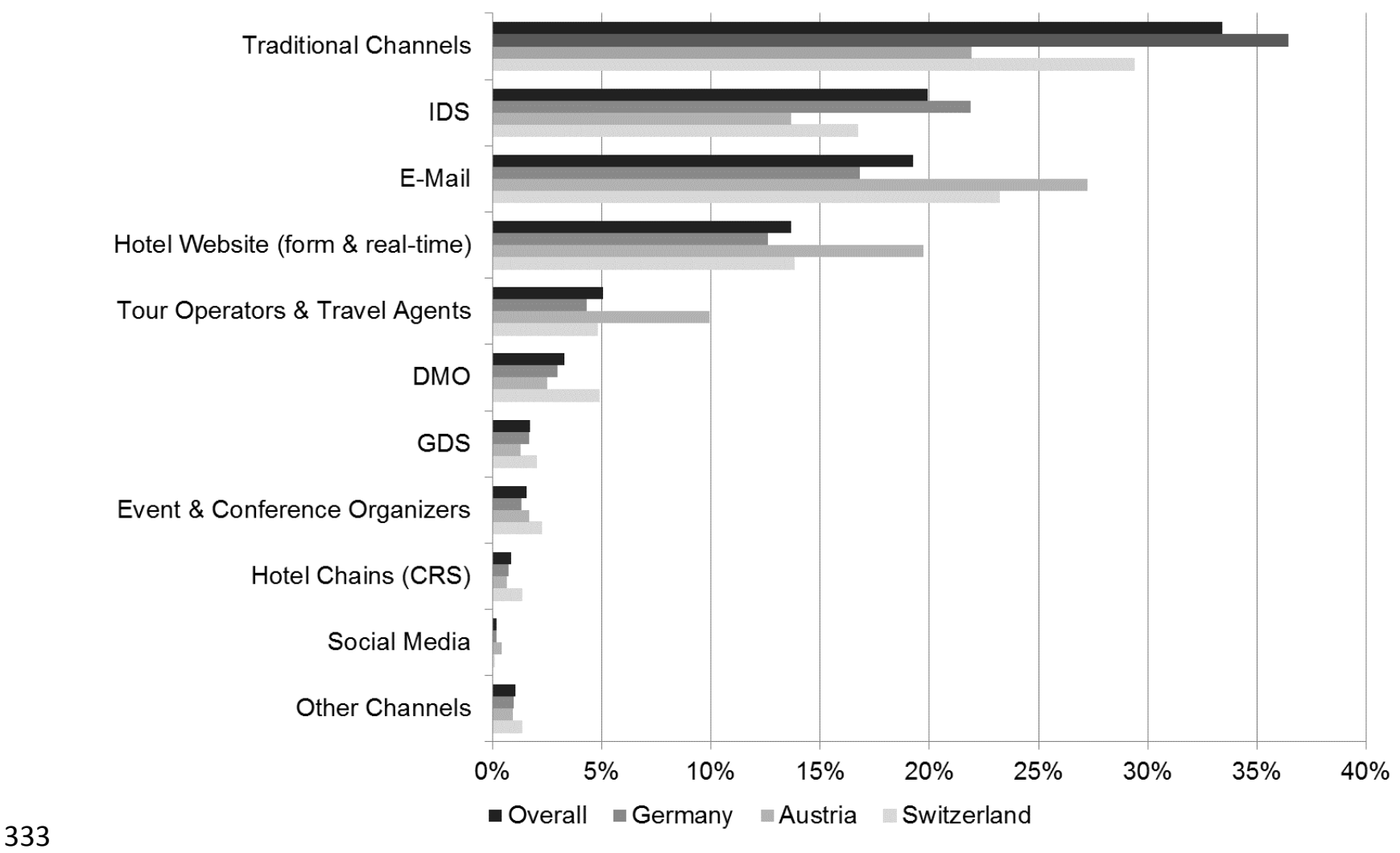

Figure 2. Distribution channel categories used in 2011

\subsection{OTA penetration and hoteliers' dependency on OTAs (RQ2)}

Looking at OTAs reveals that the three platforms used most often overall and in all three countries are Booking.com, HRS, and Hotel.de. The figures with regards to how many hoteliers use the various platforms in a target market/country (i.e., the

341 penetration rate) and the amount of online bookings generated (i.e., dependency on 342 OTAs) vary between the countries. Table 3 shows that in Germany $83.95 \%$ of 343 hoteliers distribute via HRS while the numbers are lower in Austria (65.98\%) and 344 Switzerland (58.86\%). Table 3 also shows that a high penetration rate not necessarily means high dependence on the respective platform; for instance $84.46 \%$

346 of German hotels work with Booking.com generating $29.10 \%$ of bookings. In

347 Switzerland about 5\% more hotels use this platform (89.71\%) but they generate 
349 is higher than that of German hotels. Taking into account the top three most

350 important platforms in each country, Germany is most dependent on OTAs (82.9\%)

351 followed by Switzerland (65.5\%) and Austria (59.45\%). In terms of interpreting

352 results in Table 3, one has to keep in mind that OTAs often are not single players in

353 the online market but they group under parent brands (see Table 1). For example

354 HRS and Tiscover and Hotels. de belong to the HRS Group and overall they account

355 for $42.81 \%$ of the bookings. In Germany the HRS group accounts for nearly 55\%,

356 showing a higher dependency on one organization than Switzerland on

357 Booking.com.

Table 3. Top ten OTA channels: Penetration and average amount of bookings generated (in \%)

\begin{tabular}{lcccc|cccc} 
& \multicolumn{3}{c}{ OTA channel penetration } & \multicolumn{3}{c}{$\varnothing$ amount of online bookings - channel } \\
& Overall & DE & AT & CH & Overall & DE & AT & CH \\
\hline Booking.com & 86.46 & 84.46 & 92.78 & 89.71 & 35.36 & 29.10 & 42.56 & 52.55 \\
HRS $^{1}$ & 76.85 & 83.95 & 65.98 & 58.86 & 28.34 & 36.83 & 11.24 & 9.13 \\
Hotel.de $^{1}$ & 68.17 & 78.04 & 53.61 & 42.86 & 13.03 & 16.97 & 5.65 & 3.82 \\
Expedia $^{2}$ & 28.36 & 25.34 & 29.90 & 37.71 & 2.83 & 2.15 & 3.45 & 4.77 \\
Venere $^{2}$ & 26.50 & 21.11 & 38.14 & 38.29 & 1.59 & 1.08 & 3.08 & 2.49 \\
Hotels.com & 16.09 & 15.71 & 11.34 & 20.00 & 1.26 & 1.42 & 0.81 & 0.98 \\
Unister $^{2}$ & 11.46 & 13.18 & 10.31 & 6.29 & 0.77 & 0.94 & 0.61 & 0.29 \\
Lastminute.com & 10.07 & 9.12 & 10.31 & 13.14 & 0.46 & 0.45 & 0.44 & 0.51 \\
Tiscover & 9.72 & 4.56 & 51.55 & 4.00 & 1.44 & 0.49 & 9.10 & 0.44 \\
eBookers & 7.52 & 5.24 & 3.09 & 17.71 & 0.47 & 0.28 & 0.09 & 1.30 \\
eBay & 6.71 & 6.42 & 14.43 & 3.43 & 0.59 & 0.54 & 1.08 & 0.50 \\
Bergfex & 4.75 & 0.84 & 31.96 & 2.86 & 1.28 & 0.18 & 7.88 & 1.35 \\
GHIX & 3.94 & 0.84 & 3.09 & 14.86 & 0.77 & 0.04 & 0.60 & 3.33 \\
Hotel.ch & 3.47 & 1.86 & 0.00 & 10.86 & 0.21 & 0.09 & 0.00 & 0.72
\end{tabular}

$361{ }^{1}$ HRS, Hotel.de and Tiscover belong to HRS Group. Total average amount of bookings $=42.81 \%$ 362 (DE=54.29\%, AT=25.99\%, CH=13.39\%). ${ }^{2}$ Expedia, Hotels.com and Venere belong to Expedia 363 Incorporation. Total average amount of bookings $=5.68 \%(\mathrm{DE}=4.65 \%, \mathrm{AT}=7.34 \%, \mathrm{CH}=8.24 \%)$. 
An examination of the dependency based on star rating, ownership, segment/s targeted, and location emphasizes the power of the three main players.

367 On average hoteliers rely on a portfolio of 3.61 different OTAs (STD=2.44). Germany on average uses a mix of 3.47 , Switzerland 3.78 and Austria distributes via a mix of 4.11 OTAs. $9.9 \%$ of hoteliers do not use any OTA while one hotelier is engaged with 15 different channels (Figure 3).

Figure 3. Amount of OTAs used 
379 Considering the whole sample, the data driven clustering, based on how hoteliers tap into the potential of traditional channels, electronic inquiries, online bookings, and if they take advantage of tourism partners, results in a four segment solution. The weighted simple structure index (WSSI) is 0.39 and the uncertainty reduction for 50 replications yields to an index of $95.47 \%$. Repeating the cluster analysis based country specific data is used to externally validate cluster results. The prototype table presented in Table 4 shows that the four clusters can be detected in all three countries. The wSSI for all countries is satisfactory (DE: 0.39; AT: 0.51; $\mathrm{CH}: 0.48$ ) and based on 50 replications the indices (DE: 95.62\%; AT: 98.48\%; CH: 96.57\%) provide evidence for stable clusters. In the following descriptions, each of the four paragraphs first contains a general description of each cluster, followed by differences between Germany, Austria and Switzerland in terms of group size, and finally peculiarities for each country are mentioned (Table 4).

Multi-channel distributors: This group utilizes the full potential of all possible distribution channels; generating large shares from each channel (e.g., overall 29.1\% are generated via traditional channels, $22.6 \%$ via electronic enquiries, $30.4 \%$ via GDS and other online channels, and $17.8 \%$ via tourism partners). This is the biggest group in Germany and Switzerland but only second largest in Austria. The most even usage of all channels can be found in Switzerland; in Germany this group generates fewer bookings via partners while Austria generates most via partners.

Electronic distributors: The most important channels for this group are email and online reservation forms. However, this majority of more than $55 \%$ of electronic requests is supplemented by reservations through traditional channels. The largest group is in Austria (30.84\%), followed by Switzerland (24.21\%) and Germany 
403 (17.20\%). In Austria only $14.0 \%$ of this group of hotel managers use traditional

404 channels compared to $26.6 \%$ in Germany and $26.0 \%$ in Switzerland.

405 Real-time distributors: Approximately, 60\% of all reservations of this group are real-

406 time online reservations i.e. via GDS/travel platforms etc. Real-time distribution

407 managers also get reservations via traditional channels; all other channels only play

408 a minor role. In Germany and Austria this group accounts for nearly one fourth of all

409 hoteliers (i.e., $24.58 \%$ and $23.36 \%$ respectively); while in Switzerland only $15 \%$ of

410 managers opt for this channel mix. Similar to the segment of Electronic distributors

411 this group takes less advantage of additional bookings via traditional channels.

412 Traditional distributors: More than half of all reservations are done via telephone, fax,

413 letter, and walk-ins; online channels and tourism partners only play a minor role. The

414 cluster size for the three countries is between $23 \%$ and $28 \%$. As shown in Table 4 it

415 should be noted that hoteliers in Austria (44.1\%) distribute less through traditional

416 channels than in Switzerland (53.0\%) and Germany (60.4\%). Austria basically uses

417 a combination of traditional channels and website form/ email.

Table 4. Prototype table - distribution channel mix clusters (in \%)

\begin{tabular}{|c|c|c|c|c|c|c|}
\hline & $\begin{array}{l}\text { Channel mix } \\
\text { clusters }\end{array}$ & $\begin{array}{l}\text { Cluster } \\
\text { size }\end{array}$ & $\begin{array}{l}\text { Telephone/ } \\
\text { letter/ fax/ } \\
\text { walk ins }\end{array}$ & $\begin{array}{c}\text { Website } \\
\text { form/ email }\end{array}$ & $\begin{array}{c}\text { GDS/ travel } \\
\text { platforms } \\
\text { etc. }\end{array}$ & $\begin{array}{l}\text { Tourism } \\
\text { partners }\end{array}$ \\
\hline \multirow{4}{*}{$\begin{array}{l}\overline{\bar{\sigma}} \\
\overline{0}\end{array}$} & Multi-channel & 30.06 & 29.1 & 22.6 & 30.4 & 17.8 \\
\hline & Electronic & 23.73 & 25.4 & 54.5 & 12.5 & 7.7 \\
\hline & Real-time & 21.62 & 20.9 & 13.1 & 58.9 & 7.1 \\
\hline & Traditional & 24.58 & 60.5 & 18.7 & 14.7 & 6.1 \\
\hline \multirow{4}{*}{ 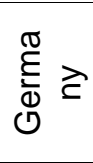 } & Multi-channel & 30.41 & 32.0 & 22.9 & 29.8 & 15.2 \\
\hline & Electronic & 17.20 & 26.6 & 55.6 & 11.6 & 6.2 \\
\hline & Real-time & 24.58 & 22.3 & 12.5 & 58.4 & 6.7 \\
\hline & Traditional & 27.80 & 60.4 & 17.2 & 15.8 & 6.6 \\
\hline \multirow{4}{*}{$\frac{\sqrt[0]{\frac{\pi}{5}}}{\frac{0}{2}}$} & Multi-channel & 22.43 & 18.7 & 31.4 & 16.6 & 33.3 \\
\hline & Electronic & 30.84 & 14.0 & 65.7 & 10.9 & 9.5 \\
\hline & Real-time & 23.36 & 15.0 & 18.6 & 53.8 & 12.6 \\
\hline & Traditional & 23.36 & 44.1 & 37.1 & 13.7 & 5.1 \\
\hline$\omega \leq$ & Multi-channel & 34.21 & 21.6 & 22.2 & 32.2 & 24.0 \\
\hline
\end{tabular}




\begin{tabular}{ll|llll} 
Electronic & 24.21 & 26.0 & 55.0 & 11.9 & 7.1 \\
Real-time & 15.26 & 16.7 & 14.8 & 60.9 & 7.6 \\
Traditional & 26.32 & 53.0 & 25.3 & 14.3 & 7.4
\end{tabular}

422 A cross-tab between class labels and countries shows that there are significant

423 differences between the countries $\left(x^{2}=79.39 ; p<0.001\right)$. Based on the overall sample, 424 results show that the channel mix approaches applied differ regarding star rating $425\left(X^{2}=26.269, p=0.011\right)$, ownership $\left(X^{2}=36.952, p<0.001\right)$, number of rooms offered 426 (average number of rooms 'Overall': $\overline{x_{\text {Multi-channel }}}=63.29, \overline{x_{\text {Electronic }}}=35.19, \overline{X_{\text {Real }}}$ 427 time $=43.07, \overline{x_{\text {Traditional }}}=39.18, p<0.001$ ), number of opening days (Mean values overall:

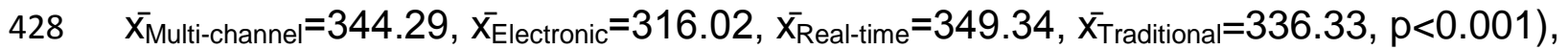
whether a hotel targets business or leisure travellers $\left(X^{2}=79.642, p<0.001\right)$, and the Iocation $\left(x^{2}=93.961, p<0.001\right)$. Overall there is a difference between the various distribution portfolio approaches with regards to the average number of off- and 432 online-channels (Mean values overall: $\overline{\bar{x}_{\text {Multi-channel }}}=9.25, \overline{\bar{x}_{\text {Electronic }}}=7.47, \overline{\bar{X}_{\text {Real-time }}}=7.88$, $433 \overline{\mathrm{X}_{\text {Traditional }}}=7.30, \mathrm{p}<0.001$ ) and the average number of OTAs used (Mean values overall: $\left.\overline{\bar{x}_{\text {Multi-channel }}}=4.71, \overline{\bar{x}_{\text {Electronic }}}=2.62, \overline{x_{\text {Real-time }}}=4.25, \overline{x_{\text {Traditional }}}=2.64, p<0.001\right)$. This difference is apparent in all countries (see Table 5). On a country level, all differences are significant for Germany. For Austria there are no differences

437 concerning ownership and target group. Differences with respect to the star rating 438 can only be confirmed for Germany.

439 Overall, with between $21.4 \%$ and $26.8 \%$ the amount of independent hotels is assigned almost equally between the various clusters. A majority of $41.2 \%$ of 5 * 441 hotels use a multi-channel distribution approach. With 9.25 off- and online channels 442 this cluster on average uses the largest number of channels, as well as the largest 
443 number of OTAs; they offer the most rooms (i.e., 63.29 rooms) and have the largest

444 share of city hotels (35.6\%). Electronic distributors on average distribute via 7.47

445 channels. They use the least amount of 2.62 OTAs and offer only 35.19 rooms;

446 cover the largest share of leisure travellers (36.8\%) and comprise the majority of

447 resort hotels (87.5\%). Real time distributors sell through a similar number of

448 channels. They use 4.25 OTAs and provide on average 43.07 rooms to the majority

449 of business travellers (83.2\%) for the longest time throughout the year (349.34 days

450 per year). Traditional distributors use the least channels (7.30), engage with 2.64

451 OTAs and offer 39.18 rooms for 336.33 days per year. Table 6 summarizes the

452 cluster profiles within the categories of the countries (only significant results are 453 presented).

Table 5. Profiles of distribution channel mix clusters for Germany, Austria and Switzerland

\begin{tabular}{|c|c|c|c|c|c|c|}
\hline & & $\begin{array}{l}\text { Multi- } \\
\text { channel }\end{array}$ & Electronic & Real-time & Traditional & $\begin{array}{l}\mathrm{X}^{2} \text { and } \\
\mathrm{p} \text {-value }\end{array}$ \\
\hline \multirow{13}{*}{ 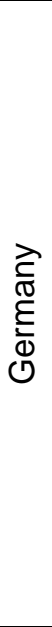 } & Not classified & $22.7 \%$ & $25.0 \%$ & $25.2 \%$ & $28.3 \%$ & \multirow{5}{*}{$\begin{array}{l}x^{2}=31.107 \\
p=0.001\end{array}$} \\
\hline & $1-2^{*}$ hotels & $18.8 \%$ & $12.5 \%$ & $28.1 \%$ & $40.6 \%$ & \\
\hline & $3^{*}$ hotels & $28.6 \%$ & $15.5 \%$ & $25.6 \%$ & $30.3 \%$ & \\
\hline & $4 *$ hotels & $44.8 \%$ & $13.4 \%$ & $19.4 \%$ & $22.4 \%$ & \\
\hline & $5^{*}$ hotels & $25.0 \%$ & $0.0 \%$ & $25.0 \%$ & $50.0 \%$ & \\
\hline & Independent hotel & $26.6 \%$ & $19.4 \%$ & $23.2 \%$ & $30.8 \%$ & \multirow{8}{*}{$\begin{array}{l}x^{2}=24.082 \\
p=0.001 \\
p<0.001 \\
p=0.007 \\
x^{2}=41.700 \\
p<0.001 \\
x^{2}=37.786 \\
p<0.001 \\
p<0.001 \\
p<0.001\end{array}$} \\
\hline & $\varnothing$ number of rooms & 56.96 & 29.80 & 40.28 & 38.71 & \\
\hline & (STD) & $(60.2)$ & $(27.2)$ & (51.5) & $(43.7)$ & \\
\hline & $\begin{array}{l}\varnothing \text { no. opening days } \\
\text { (STD) }\end{array}$ & $\begin{array}{c}351.41 \\
(26.7)\end{array}$ & $\begin{array}{c}337.41 \\
(40.6)\end{array}$ & $\begin{array}{l}349.53 \\
(30.5)\end{array}$ & $\begin{array}{c}345.02 \\
(34.2)\end{array}$ & \\
\hline & Leisure guests & $26.4 \%$ & $29.6 \%$ & $17.6 \%$ & $26.4 \%$ & \\
\hline & Share of city hotels & $33.8 \%$ & $10.6 \%$ & $27.8 \%$ & $27.8 \%$ & \\
\hline & $\varnothing$ number of off-/online & 9.11 & 6.78 & 7.94 & 7.28 & \\
\hline & $\varnothing$ number of OTAs & 4.48 & 2.27 & 4.18 & 2.59 & \\
\hline \multirow{6}{*}{ 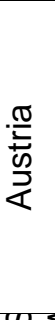 } & $\varnothing$ number of rooms & 86.43 & 46.42 & 65.32 & 37.86 & \multirow{7}{*}{$\begin{array}{l}p<0.001 \\
p<0.001 \\
x^{2}=35.588 \\
p<0.001 \\
p=0.004 \\
p=0.001 \\
x^{2}=16.910\end{array}$} \\
\hline & $\varnothing$ no onening davs & $\begin{array}{l}\text { (0U.5) } \\
329.96\end{array}$ & $\begin{array}{l}(24.9) \\
28182\end{array}$ & $\begin{array}{l}(34.0) \\
35724\end{array}$ & $\begin{array}{l}(22.8) \\
325.00\end{array}$ & \\
\hline & (STD) & $(48.7)$ & $(67.0)$ & $(17.7)$ & $(43.4)$ & \\
\hline & Share of city hotels & $27.3 \%$ & $21.2 \%$ & $45.5 \%$ & $6.1 \%$ & \\
\hline & $\varnothing$ number of off-/online & 8.56 & 8.45 & 7.45 & 6.29 & \\
\hline & $\varnothing$ number of OTAs & 5 & 3.42 & 5.35 & 2.57 & \\
\hline o & Independent hotel & $27.5 \%$ & $35.8 \%$ & $15.0 \%$ & $21.7 \%$ & \\
\hline
\end{tabular}




$\varnothing$ number of rooms
(STD)
$\varnothing$ no. opening days
(STD)
Leisure guests (within
category)
Share of city hotels
$\varnothing$ number of off-/online
channels
$\varnothing$ number of OTAs

458

\section{Discussion and Conclusion}

\section{$\underline{6.1 \text { Theoretical discussion }}$}

462 This study's contribution to knowledge is twofold: Content wise, it looks at the

463 distribution channel portfolio hoteliers choose, the dependency on OTAs and countries differences. From a methodological point of view, it presents one of the few studies dealing with supply side based cluster analysis and the external validation of the cluster results, using data from different countries.

467 Contrary to what many previous studies predicted (Kasavana and Singh 2001; O'Connor and Frew 2002) results of this research (RQ1) show that traditional channels (i.e., telephone, fax, letters and walk-ins) still play a dominant role in terms of distributing hotel rooms. Even though for German and Swiss hoteliers, traditional

471 channels continue to be most important, in Austria, bookings via email overtook

472 traditional channels. This may be supported by results of a study by Schegg (2014)

473 that showed that Austrian hotels use more ICT tools and are ahead compared to the

474 hotels in the two other countries when it comes to technology adoption. The

475 multivariate results of the cluster analysis and other studies support this higher

476 usage of cheaper online channels (O'Connor and Frew 2004; Brown and 
477 Kaewkitipong 2009). Compared to Germany and Switzerland, Austria is also different concerning the cluster labelled Traditional distributors. First of all, this group is smaller in Austria, it distributes less via telephone, fax, letter, or walk-ins and it takes advantage of the less expensive direct online channels (O'Connor and Frew 2004) such as website forms and email.

Looking at distribution channel categories, hoteliers on average rely on a portfolio of 8.06 channels. In terms of booking, DMOs and social media only play a minor role; confirming that these channels are more important for market exposure and information provision (Vermeulen and Seegers 2009; Xiang and Law 2012). Compared to OTAs who have a strong position as a booking channel, DMOs may have deficiencies concerning competitive factors such as resources (e.g. finances, knowledge), sales efficiency (i.e. conversion rates) and market reach (Tso and Law 2005). OTAs have a global reach, they can build on economies of scope and scale, aggregate products, offer deals in multiple languages and provide a convenient 'onestop-shop' (Kim, Bojanic, and Warnick 2009, O’Connor and Frew 2004). On average hoteliers use 3.61 OTAs. Interestingly, there is a group of hotels (about 10\%) who do not sell anything via OTAs; thus they avoid dependency and high commission rates but at the same time miss opportunities concerning market coverage (O'Connor and Frew 2004).

Findings about the dependency of hoteliers on OTAs (RQ2) show that Booking.com's penetration rate is highest in Austria. The penetration rate in Switzerland is high too but their average number of bookings from Booking.com is above 50\%; thus their dependency is higher than in Austria and Germany. Results demonstrate that a high penetration of a certain intermediary does not necessarily mean a similar high dependency. High penetration puts opportunities in terms of 
increasing visibility in place (Buhalis 1999) while high dependency means loss of control about the product and marketing activities (Toh, Raven, and DeKay 2011).

The dominant players leverage market knowledge as they have the data, the knowhow and the personnel to reveal insights through data mining (Kim, Bojanic, and Warnick 2009; Gazzoli, Kim, and Palakurthi 2008; Toh, Raven, and DeKay 2011).

Examining OTAs with regards to their parent brands uncovers an oligopolistic market structure. Although, the most relevant OTA used by hoteliers is Priceline, the highest penetration is observed with HRS, followed by Expedia Inc. Especially German hotels are highly dependent on the HRS group risking to be controlled with regards to pricing, product policies, promotion and other marketing activities (Toh, Raven, and DeKay 2011; Carroll and Siguaw 2003).

Regarding the distribution channel mix chosen by hoteliers (RQ3) we can see that Multi-channel distributers is the biggest group overall in Germany and Switzerland. Using multiple channels maximises the chance to of raising awareness and selling (Chan and Law 2006; Abou-Shouk, Megicks, and Lim 2012); however, at the same time an growing amount of channels increases distribution management complexity (Kracht and Wang 2010). Austria is somewhat different again; the group of Electronic distributors is the biggest there. This shows the focus on direct distribution via website forms and emails which diminishes the risk of dependency (Toh, Raven, and DeKay 2011; Carroll and Siguaw 2003) while taking advantage of cheaper online channels (Ip, Law, and Lee 2011). With regards to Multi-channel distributors, Austria relies most on tourism partners. Hence, there is evidence that not only the importance of certain OTAs (Schegg 2014) but also the importance of NTOs, associations, travel agencies and event-organizers differs between countries. A 
526 follow-up study should investigate whether these results are an indication that

527 Austria is more successful in forming strategic alliances (Ashton and Scott 2011).

528 Profiling the cluster groups shows that there are significant differences between the 529 three countries concerning market structure variables (Berne, Garcia-Gonzalez, and 530 Mugica 2012; Werthner and Ricci 2004). More specifically, the distribution channel 531 mix chosen differs in terms of star-rating, the amount of opening days, number of 532 rooms offered, ownership, location, target group, and amount of channels and OTAs 533 used. This confirms that service outputs such as product, target market sophistication, and resources-based aspects such as competitive strength and company size have to be considered in order to choose the right channel mix 536 (Coelho and Easingwood 2008).

537 Finally, from a methodological point of view this article aligns with the few available studies using supply side data as a segmentation base (Claver-Cortés, MolinaAzorín, and Pereira-Moliner 2006). Moreover, results have also been successfully 540 validated externally using different samples.

\section{$\underline{6.2 \text { Managerial implications }}$}

543 As mentioned earlier, distribution portfolio profiles facilitate learning from common 544 strategies used by hotels with different characteristics such as target group and star545 rating.

546 In all three countries Multichannel distributors engage in the biggest number of 547 channel categories and OTAs and are most prevalent in bigger (around 65 rooms) 
548 five star city hotels, while smaller (around 35 rooms) resort hotels are the most dominant in the group of electronic distributors who use the least amount of OTAs.

550 As findings revealed differences between countries, strategies must be applied accordingly (see Table 5). Based on the results of this study it is recommended that hoteliers in Germany and Switzerland may observe how Austrian hoteliers are more successful in terms of generating direct bookings via email and forms. Hoteliers may be able to see how Austrian hotel websites are designed and how they trigger selling products directly to the customers (Ip, Law, and Lee 2011). Further, "findability" of hotel owned websites might be an issue worth looking at (Law and Hsu 2006; Xiang, Wöber, and Fesenmaier 2008).

558 Given the high reliance of Switzerland on Booking.com, it shows that this particular OTA has a very central position in the distribution network, which means this player is gaining power (Zeng and Gerritsen 2014). Swiss hoteliers need to make sure that Booking.com is not taking control over their product and marketing strategy (Carroll and Siguaw 2003). Best would be to convince travellers to book directly. This could be done by investing in attractive and well-positioned websites (Ip, Law, and Lee 2011; Chung and Law 2003) and by setting up attractive loyalty programmes (Vermeulen and Seegers 2009). Hoteliers' need to make sure not only to benefit in terms of market coverage but to maximize the value gained from being part of a network (Ford, Wang, and Vestal 2012). The same is true for German hotels when it comes to their dependency on the HRS group.

Out of the three countries Austria is the most independent. Thus, it is recommended to observe Austrian hoteliers and how they succeed to have a high penetration rate 571 (i.e., availability of benefits OTAs come with if needed) but at the same time being 
572 less dependent (i.e., having full control). Given the dependency of all countries on certain OTAs and the fact that the complexity of distribution tends to further increase (Kracht and Wang 2010) hoteliers need to constantly monitor their relationships to make sure that they maximize the value that can be gained from being part of a distribution network (Ford, Wang, and Vestal 2012).

\subsection{Limitations and Future Research}

This study has some limitations to be considered. Since, we used a convenience sample there are some hotel star-rating groups, which are underrepresented.

Austria, Germany and Switzerland where analysed; however, an in-depth understanding of other markets, for instance, rising source markets, such as China (who uses different channels due to government restrictions) is essential allowing hoteliers to successfully distribute their services globally. Also, a longitudinal study revealing insights concerning changes of power balances between network members is appreciated (Berne, Garcia-Gonzalez, and Mugica 2012; Werthner and

Ricci 2004). Generally, there is a need for more studies to get a better understanding of the role and the centrality of various players.

\section{References}

Abou-Shouk, Mohamed, Phil Megicks, and Wai Mun Lim. 2012. "Perceived Benefits and E-Commerce Adoption by SME Travel Agents in Developing Countries: Evidence From Egypt." Journal of Hospitality \& Tourism Research, April.

Ashton, Ann Suwaree, and Noel Scott. 2011. "Hotel Restaurant Co-Branding: The Relationship of Perceived Brand Fit with Intention to Purchase." Journal of Vacation Marketing 17 (4): 27585.

Ball, Michael O., and Maurice Queyranne. 2009. "Toward Robust Revenue Management: Competitive Analysis of Online Booking." Operations Research 57 (4): 950-63. Bennett, Marion M., and Chi-Wen Kevin Lai. 2005. "The Impact of the Internet on Travel Agencies in Taiwan." Tourism and Hospitality Research 6 (1): 8-23. 
Berne, Carmen, Margarita Garcia-Gonzalez, and Jose Mugica. 2012. "How ICT Shifts the Power Balance of Tourism Distribution Channels." Tourism Management 33 (1): 205-14.

Brewer, P., A. H. Feinstein, and B. Bai. 2006. "Electronic Channels of Distribution: Challenges and Solutions for Hotel Operators." FIU Hospitality and Tourism Review 24 (2): 68-77.

Brodbeck, Felix C., Michael Frese, Staffan Akerblom, Giuseppe Audia, Gyula Bakacsi, Helena Bendova, Domenico Bodega, et al. 2000. "Cultural Variation of Leadership Prototypes across 22 European Countries." Journal of Occupational and Organizational Psychology 73 (1): 129.

Brown, David H., and Laddawan Kaewkitipong. 2009. "Relative Size and Complexity: E-Business Use in Small and Medium Sized Tourism Enterprises in Thailand." Journal of Enterprise Information Management 22 (1/2): 212-31.

Brown, J.R., R.F. Lusch, and D.D. Muehling. 1983. "Conflict and Power-Dependence Relations in Retailer-Supplier Channels." Journal of Retailing 59 (4): 53-80.

Buhalis, Dimitrios. 1999. "Information Technology for Small and Medium-Sized Tourism Enterprises: Adaptation and Benefits." Journal of Information Technology \& Tourism 2 (2): 79-95.

- - . 2000. "Relationships in the Distribution Channel of Tourism." International Journal of Hospitality \&amp; Tourism Administration 1 (1): 113-39.

-- . 2003. ETourism : Information Technology for Strategic Tourism Management. Harlow, England: Financial Times Prentice Hall.

Buhalis, Dimitrios, and Rob Law. 2008. "Progress in Information Technology and Tourism Management: 20 Years on and 10 Years after the Internet-The State of eTourism Research." Tourism Management 29 (4): 609-23.

Carroll, Bill, and Judy Siguaw. 2003. "The Evolution of Electronic Distribution: Effects on Hotels and Intermediaries." The Cornell Hotel and Restaurant Administration Quarterly 44 (4): 38-50.

Cespedes, Frank V., and E. Raymond Corey. 1990. "Managing Multiple Channels." Business Horizons 33 (4): 67-77.

Chan, Steven, and Rob Law. 2006. "Automatic Website Evaluations: The Case of Hotels in Hong Kong." Information Technology \& Tourism 8 (3-4): 255-69.

Chiu, Hung-Chang, Yi-Ching Hsieh, Jinshyang Roan, Kuan-Jen Tseng, and Jung-Kuei Hsieh. 2011. "The Challenge for Multichannel Services: Cross-Channel Free-Riding Behavior." Electronic Commerce Research and Applications 10 (2): 268-77.

Chung, Tony, and Rob Law. 2003. "Developing a Performance Indicator for Hotel Websites." International Journal of Hospitality Management 22 (1): 119-25.

Coelho, Filipe, and Chris Easingwood. 2003. "Multiple Channel Structures in Financial Services: A Framework." Journal of Financial Services Marketing 8 (1): 22-34.

- - . 2008. "A Model of the Antecedents of Multiple Channel Usage." Journal of Retailing and Consumer Services 15 (1): 32-41.

Coughlan, A.T., E. Anderson, L.W. Stern, and A.I. El-Ansary. 2001. Marketing Channels (6th Ed.). Upper Saddle River, NJ:: Prentice Hall.

David Forlani, and Madhavan Parthasarathy. 2003. "Dynamic Market Definition: An International Marketing Perspective." International Marketing Review 20 (2): 142-60.

Dolnicar, Sara. 2002. "A Review of Data-Driven Market Segmentation in Tourism." Journal of Travel \& Tourism Marketing 12 (1): 1-22.

Enz, Cathy A. 2003. "Hotel Pricing in a Networked World." The Cornell Hotel and Restaurant Administration Quarterly 44 (1): 4-5.

EXPEDIA INC. 2014. "Expedia Brands." http://www.expediainc.com/expedia-brands/.

Filieri, Raffaele, and Fraser McLeay. 2013. "E-WOM and Accommodation: An Analysis of the Factors That Influence Travelers' Adoption of Information from Online Reviews." Journal of Travel Research, March. 
Filser, M., and F Eggers. 2014. "Entrepreneurial Orientation and Firm Performance : A Comparative Study of Austria, Liechtenstein and Switzerland." South African Journal of Business Management 45 (1): 55-65.

Ford, Robert C., Youcheng Wang, and Alex Vestal. 2012. "Power Asymmetries in Tourism Distribution Networks." Annals of Tourism Research 39 (2): 755-79.

Gazzoli, Gabriel, Woo Gon Kim, and Radesh Palakurthi. 2008. "Online Distribution Strategies and Competition: Are the Global Hotel Companies Getting It Right?" International Journal of Contemporary Hospitality Management 20 (4): 375-87.

Hotelplan Holding. 2014. "Hotelplan Holding - Ueber Uns." http://www.hotelplan.com/ueber-uns/. HRS Group. 2014. "HRS at a Glance." http://www.hrs.com/web3/showCmsPage.do?clientld=ZW5fX05FWFQ-\&cid=432\&pageld=standard-01841.

Inversini, Alessandro, and Lorenzo Masiero. 2014. "Selling Rooms Online: The Use of Social Media and Online Travel Agents." International Journal of Contemporary Hospitality Management 26 (2): 272-92.

Ip, Crystal, Rob Law, and Hee "Andy" Lee. 2011. "A Review of Website Evaluation Studies in the Tourism and Hospitality Fields from 1996 to 2009." International Journal of Tourism Research 13 (3): 234-65.

Kang, Bomi, Kathleen Pearl Brewer, and Seyhmus Baloglu. 2007. "Profitability and Survivability of Hotel Distribution Channels." Journal of Travel \& Tourism Marketing 22 (1): 37-50.

Kasavana, Michael L., and A. J. Singh. 2001. "Online Auctions." Journal of Hospitality \& Leisure Marketing 9 (3-4): 127-40.

Kaynak, Erdener, and Paul Herbig. 2014. Handbook of Cross-Cultural Marketing. Routledge.

Keller, Kevin Lane. 2010. "Brand Equity Management in a Multichannel, Multimedia Retail Environment." Journal of Interactive Marketing 24 (2): 58-70.

Kim, Jinhoo, David C. Bojanic, and Rodney B. Warnick. 2009. "Price Bundling and Travel Product Pricing Practices Used by Online Channels of Distribution." Journal of Travel Research 47 (4): 403-12.

Kracht, John, and Youcheng Wang. 2010. "Examining the Tourism Distribution Channel: Evolution and Transformation." International Journal of Contemporary Hospitality Management 22 (5): 736-57.

Lau, Kin-nam, Kam-hon Lee, Pong-yuen Lam, and Ying Ho. 2001. "Web-Site Marketing: For the Travel-and-Tourism Industry." The Cornell Hotel and Restaurant Administration Quarterly 42 (6): 55-62.

Law, Rob. 2009. "Disintermediation of Hotel Reservations: The Perception of Different Groups of Online Buyers in Hong Kong." International Journal of Contemporary Hospitality Management 21 (6): 766-72.

Law, Rob, and Cathy H. C. Hsu. 2006. "Importance of Hotel Website Dimensions and Attributes: Perceptions of Online Browsers and Online Purchasers." Journal of Hospitality \& Tourism Research 30 (3): 295-312.

Law, Rob, and Giri Jogaratnam. 2005. "A Study of Hotel Information Technology Applications." International Journal of Contemporary Hospitality Management 17 (2): 170-80.

Law, Rob, Rosanna Leung, Ada Lo, Daniel Leung, and Lawrence Hoc Nang Fong. 2015. “Distribution Channel in Hospitality and Tourism: Revisiting Disintermediation from the Perspectives of Hotels and Travel Agencies." International Journal of Contemporary Hospitality Management 27 (3): 431-52.

Lee, Hee "Andy," Basak Denizci Guillet, and Rob Law. 2013. "An Examination of the Relationship between Online Travel Agents and Hotels A Case Study of Choice Hotels International and Expedia.com." Cornell Hospitality Quarterly 54 (1): 95-107. 
Louvieris, Panos, John Driver, and Jan Powell-Perry. 2003. "Managing Customer Behaviour Dynamics in the Multi-Channel E-Business Environment: Enhancing Customer Relationship Capital in the Global Hotel Industry." Journal of Vacation Marketing 9 (2): 164-73.

Lowe, Michelle S., Allan M. Williams, Gareth Shaw, and Katherine Cudworth. 2012. "Self-Organizing Innovation Networks, Mobile Knowledge Carriers and Diasporas: Insights from a Pioneering Boutique Hotel Chain." Journal of Economic Geography 12 (5): 1113-38.

Marcussen, Carl Henrik. 2008. "Trends in European Internet Distribution - of Travel and Tourism Services." Trends in European Internet Distribution - of Travel and Tourism Services. http://195.130.87.21:8080/dspace/handle/123456789/864.

Martenson, Rita. 1987. "Is Standardisation of Marketing Feasible in Culture-Bound Industries? A European Case Study." International Marketing Review 4 (3): 7-17.

Mazanec, Joseph. 2008. "TRN32 for Windows." TRN32 for Windows. http://www.wu.ac.at/itf/downloads/software/trn32.

Michopoulou, Eleni, and Dimitrios Buhalis. 2008. "Performance Measures of Net-Enabled Hypercompetitive Industries: The Case of Tourism." International Journal of Information Management 28 (3): 168-80.

Mills, Juline E., and Rob Law. 2013. Handbook of Consumer Behavior Tourism and the Internet. Routledge.

Morosan, Cristian, and Miyoung Jeong. 2008. "Users' Perceptions of Two Types of Hotel Reservation Web Sites." International Journal of Hospitality Management 27 (2): 284-92.

Nash, T. 2001. Relationship Management. Greenwich: Director's Publisher.

O'Connor, P., and A. J. Frew. 2002. "The Future of Hotel Electronic Distribution: Expert and Industry Perspectives." Cornell Hotel and Restaurant Administration Quarterly 43 (3): 33-45.

O'Connor, Peter. 2008. Electronic Distribution. Vol. Handbook of Hospitality Operations and IT. Routledge.

O'Connor, Peter, and Andrew J. Frew. 2004a. "An Evaluation Methodology for Hotel Electronic Channels of Distribution." International Journal of Hospitality Management 23 (2): 179-99.

-- . 2004b. "An Evaluation Methodology for Hotel Electronic Channels of Distribution." International Journal of Hospitality Management 23 (2): 179-99.

Orbiz Worldwide. 2014. "Orbiz Worldwide - Who We Are." https://careers.orbitz.com/who-weare.html.

Palmer, Adrian, and Patrick McCole. 1999. "The Virtual Re-Intermediation of Travel Services: A Conceptual Framework and Empirical Investigation." Journal of Vacation Marketing 6 (1): 33-47.

Pauwels, Koen, and Scott A. Neslin. 2015. "Building With Bricks and Mortar: The Revenue Impact of Opening Physical Stores in a Multichannel Environment." Journal of Retailing 91 (2): 182-97.

Pearce, Douglas G. 2008. "Beyond Tiers: A Network Approach to Tourism Distribution." Tourism Analysis 13 (5-1): 517-30.

Pfeffer, Jeffrey. 1992. Managing with Power: Politics and Influence in Organizations. Harvard Business Press.

PhoCusWright. 2011. "Pan-European Online Travel Agency Landscape." http://www.phocuswright.com/products/2716.

Priceline Group. 2014. "Priceline Group." http://ir.pricelinegroup.com/.

Sabre Holdings Corp. 2014. "Sabre Holdings Corporation Copyright and Trademark Notice." http://www.sabre.com/about/copyright-and-trademark-notice.

Scaglione, Miriam, and Roland Schegg. 2015. "The Impact of Attribute Preferences on Adoption Timing of Hotel Distribution Channels: Are OTAs Winning the Customer Race?" In Information and Communication Technologies in Tourism 2015, edited by lis Tussyadiah and Alessandro Inversini, 681-93. Springer International Publishing. http://link.springer.com/chapter/10.1007/978-3-319-14343-9_49. 
Schegg, R. 2014. "European Hotel Distribution Study: The Rise of Online Intermediaries. Special Focus Switzerland." http://www.hotelier.de/news/2008/21613/Ranking-derHotelbuchungsportale-HRS.de-weiterhin-auf-Platz-1.

Schegg, R., B. Stangl, M. Fux, and A. Inversini. 2013. "Distribution Channels and Management in the Swiss Hotel Sector." In Ng, Z., Proocedings of Information and Communication Technologies in Tourism 2013, 554-65. Innsbruck: Springer.

Simchi-Levi, David, S. David Wu, and Zuo-Jun Shen. 2004. Handbook of Quantitative Supply Chain Analysis: Modeling in the E-Business Era. Taylor \& Francis.

Starkov, Max, and Jason Price. 2007. "What Hot Internet Marketing Topics Are on the Minds of Hoteliers?" HeBs Digital.

http://cdn.hebsdigital.com/articles/pdf/2007/Aug07HeBSArticleHotInternetMarketingTopics ontheMindsofHoteliers.pdf.

Szabo, Erna, Felix C. Brodbeck, Deanne N. Den Hartog, Gerhard Reber, Jürgen Weibler, and Rolf Wunderer. 2002. "The Germanic Europe Cluster: Where Employees Have a Voice." Journal of World Business, Leadership and Cultures Around the World: Findings from GLOBE, 37 (1): 55-68.

Thill, K., B.C. Venegas, and S Groblschegg. 2014. "HR Roles and Activities. Empirical Results from the DACH Region and Implications for a Future Development of the HR Profession." International Journal of Business and Management 2 (4).

Tkaczynski, Aaron, and Nina K. Prebensen. 2012. "French Nature-Based Tourist Potentials to Norway: Who Are They?" Tourism Analysis 17 (2): 181-93.

Toh, Rex S., Peter Raven, and Frederick DeKay. 2011. "Selling Rooms: Hotels vs. Third-Party Websites." Cornell Hospitality Quarterly 52 (2): 181-89.

Top Hotel. 2008. "Ranking Der Top-Hotelbuchungsportale." http://www.hotelier.de/news/2008/21613/Ranking-der-Hotelbuchungsportale-HRS.deweiterhin-auf-Platz-1.

Tourism Alliance. 2014. "UK Tourism Statistics 2014". TourismAlliance - The Voice of Tourism.

TraveICLICK. 2009. http://www.travelclick.net/information-center/bookings-by-channel.cfm.

Tse, Alan Ching-biu. 2003. "Disintermediation of Travel Agents in the Hotel Industry." International Journal of Hospitality Management 22 (4): 453-60.

Tso, Angie, and Rob Law. 2005. "Analysing the Online Pricing Practices of Hotels in Hong Kong." International Journal of Hospitality Management 24 (2): 301-7.

Vermeulen, Ivar E., and Daphne Seegers. 2009. "Tried and Tested: The Impact of Online Hotel Reviews on Consumer Consideration." Tourism Management 30 (1): 123-27.

Werthner, Hannes, and Francesco Ricci. 2004. "E-Commerce and Tourism." Commun. ACM 47 (12): 101-5.

Xiang, Zheng, and Rob Law. 2012. "Online Competitive Information Space for Hotels: An Information Search Perspective." Journal of Hospitality Marketing \& Management 0 (ja).

Xiang, Zheng, Karl Wöber, and Daniel R. Fesenmaier. 2008. "Representation of the Online Tourism Domain in Search Engines." Journal of Travel Research 47 (2): 137-50.

Yan, Ruiliang, Peijun Guo, John Wang, and Nawel Amrouche. 2011. "Product Distribution and Coordination Strategies in a Multi-Channel Context." Journal of Retailing and Consumer Services 18 (1): 19-26.

Zeng, Benxiang, and Rolf Gerritsen. 2014. "What Do We Know about Social Media in Tourism? A Review." Tourism Management Perspectives 10 (April): 27-36. 